\title{
ASSESSMENT OF THE INFLUENCE OF EMPLOYMENT ON PERSONAL DEVELOPMENT OF YOUTH WITH DISABILITIES IN ELGEYO-MARAKWET COUNTY, KENYA
}

\author{
William Kibet Kurumei ${ }^{1 i}$, \\ Collins O. Ogogo², \\ Edward Kochung;, \\ Cecilia Kimani ${ }^{4}$ \\ ${ }^{1}$ Dean of Students, \\ Department of Special Needs Education, \\ Mount Kenya University, \\ Kenya \\ ${ }^{2}$ Senior Lecturer, Dr., \\ Educational Communications, \\ Department of Education Technology \\ Machakos University, \\ Kenya \\ ${ }^{3}$ Dean, Faculty of Education, \\ Department of Special Needs, \\ Maseno University, \\ Kenya \\ ${ }^{4}$ Senior Lecturer, Dr., \\ Department of Special Needs, \\ Mount Kenya University, \\ Kenya
}

\begin{abstract}
:
Disability is a natural part of the human experience and therefore should not affect the rights of individuals to live independently, contribute to society, enjoy full inclusion in education and pursue a meaningful career. However, youth with disabilities (YWDs) in Elgeyo Marakwet Kenya face socio-economic discrimination communally. Exclusion, isolation, abuse and lack of educational opportunities exist in Elgeyo-Marakwet County, Kenya. They do not enjoy the same human rights or equal access to goods and services as their peers without disabilities. The main objective of this study was to assess the influence of employment on personal development of youth with disabilities in ElgeyoMarakwet County Kenya. Two theories, Catherine Sanderson's (2010) theory of sociocultural perspective and Adams Stacy's (1965) equity theory were studied to enable an understanding of the influence of the socio-cultural support services on personal development of youth with disabilities. A mixed methodology, using a triangulation
\end{abstract}

i Correspondence: email wk.kuru@gmail.com 
design with both quantitative and qualitative research was employed in this study to realize the objectives. The study targeted a total population of 492 of youth with disabilities, 320 parents of youth with disabilities in and out of school and 19 government officers. Sample size determination formula by Krejcie and Morgan (1970) was used to obtain the required sample of the youth with disabilities and their parents. Simple random sampling was used to select youth with disabilities and parents while purposive sampling was used to select government officers (key informants). A sample of 289 youth with disabilities, 175 parents and 19 government officers were picked for the study. Data was collected using questionnaires, interview schedule and an observation checklist. To determine content validity of the instruments, the supervisors were presented with the research instruments prior to the actual study. Their comments were adopted in modifying the instruments. The reliability of the instruments was established through a pilot study where a coefficient of Cronbach's Alpha was determined, which was 0.741. Quantitative data were analyzed using descriptive statistics, while qualitative data were analysed thematically as the themes emerged. Employment contributed $19.7 \%$ to personal development of youth with disabilities. The study recommended, among others, funding of youth with disabilities support groups, initiating follow up support programs for youth with disabilities and wholly focusing on services that ensure that the 'best' is offered to the youth with disabilities as per government's policies. The findings of this study may help in improving the education policy to have a focus on transition plans for youth with disabilities after school.

Keywords: youth with disabilities, employment, personal development

\section{Introduction}

Disability is universal. In the past disabled individuals had been isolated, mistreated and ignored (Anderson 2004), but constant practice and research in advanced countries like Sweden, United Kingdom, Australia, United states (US) and Canada, have shown positive dependence between development growth and strategic social change by, with, and for persons with disabilities (Human Resource Development Canada (HRDC), 2002). According to the United Nations Children fund (1999), youth with disabilities all over the continent were left out of economic activities. They were not included in activities that generated wealth, while ordinary youth were not subjected to that type of treatment. Hollar (2005) observed that this group of youth was the most ignored and whose human rights were also taken for granted. Moreover, according to United Nations Children Fund (1999) youth with disabilities both male and female were more discriminated against and had profound social and economic inequities when examined against ordinary persons, even in advanced countries.

A large proportion of youth with disabilities experienced exclusion and abuse almost always and also lacked economic and educational opportunities. youth with disabilities are isolated and are amongst the world's poorest young people. Their basic 
rights are ignored and are neither recognized nor accepted by society (Hollar, 2005). Observations were also made by Mitra, Posarac and Vick (2013) that youth with disabilities were discriminated in areas of education, employment and social activities just as adults who also suffered disabilities. It was in this light that the United Nations brought about the convention on the rights of persons with disabilities to force in December 2006 to bring democracy to all persons, young and old who had disabilities.

Nevertheless, Roggero et al. (2005) noted that employers and other persons generally had no patience with youth with disabilities when they made a mistake at work. They would be labelled unemployable. Young women with disabilities even with a good education would have it even rougher because of gender discrimination and might take very long before getting a job (Roggero et al, 2005). This continued despite assent by many of these nations to the law covering the entire basic rights and freedoms that all humans are guaranteed (UDHR) (CRC 2006). The formal deliberative assembly of the mandated delegates on the rights of the child was approved by the UN general assembly (2006). The African Union (AU) member states then accepted the African document - Charter on the guaranteed basic rights and freedoms of the child. The document affirms the freedoms of children with disabilities to security under conditions that would encourage self-reliance, enabled active participation in community and guaranteed their dignity (Anderson, 2004).

\subsection{Statement of the Problem}

The United Nations Convention on Rights of Persons with Disabilities (United Nations, 2006) put forward a policy on non-discrimination of the child regardless of race, religion, gender or disability. Likewise, the Kenya Disabilities Act of 2003, a Kenyan act of parliament, was meant to ensure that Persons with disabilities were accorded their rights and rights of rehabilitation to succeed in opportunities like ordinary persons. These laws aim at facilitating equal access to all socio-cultural support services by youth with disabilities. Despite the many legislations and laws to guard the rights of persons with disabilities, there still exist profound discrimination in various sectors of contemporary society. Anderson (2004) indicated that in the past disabled individuals had been isolated, mistreated and ignored. Observations were also made by Mitra, Posarac and Vick (2013) that youth with disabilities were discriminated in areas of education, employment and social activities just as adults who also suffered disabilities. According to International Labour Organization (2002), people with disabilities' opportunities of being employed were low because they did not acquire the practical knowledge and theoretical qualifications to integrate well in society.

Youth with disabilities in Elgeyo-Marakwet County were not fully enjoying these rights because of lack of policy operationalization. Some of these challenges are that they were still isolated and ignored in many spheres of society like in access of education and vocational facilities, unemployment, inadequate and inaccessible health facilities and community's negative perception. According to the National Council on Disabilities (2000b), youth with disabilities were highly disadvantaged in gaining outcomes of full 
participation in societal activities because of a myriad of barricades to the full access of civil and human rights. In Elgeyo-Marakwet County, it is a common phenomenon to witness youth with disabilities begging in the streets and neighbourhoods, without any meaningful economic activities. In addition, there still exist cases of parents or guardians of youth with disabilities who conceal the whereabouts of their children especially those with mental disabilities by locking them away from the glare of the public or restricting their freedom of movement by chaining them under trees. For those who have mobility, they are rejected, isolated from main public gatherings such as community wedding ceremonies and parties. This gives an overall impression of negative attitude towards them and diminishes their personal development.

Research showed that provision of socio-cultural support services to youth with disabilities was very critical towards their personal development (National Council on Disability, 2000b). In a review of literature by Hasnain et al (2003), on outreach and people with disabilities from diverse cultures, Hasnain et al (2003), indicated that despite programs being available to youth with disabilities regarding their personal development, there was very little evidence regarding the influence that socio-cultural support services like, employment, health, education and vocational training as well as community perception had on personal development (Hasnain, Sotnik \& Ghiloni, 2003; Edwards \& Livingston, 1990). This applies to developing nations, Kenya included. Involvement in disability programs by Kenyan government, Elgeyo-Marakwet County and development agencies that support them has been negligible, despite a sizeable population proportion of $2.8 \%$ (Socio-economic Atlas, 2014).

This way, there appeared to be inadequate data to inform best practices towards personal development of youth with disabilities, despite the fact that personal development is one of the priorities of education in Kenya National Goals of Education (2013). Furthermore, other socio-cultural services such as family resources, communitybased organizations among other services were available in the County, but inadequate. Thus, the current study assessed the influence of socio-cultural support services on personal development of youth with disabilities in Elgeyo-Marakwet County, Kenya.

\subsection{Hypothesis}

$\mathbf{H}_{0:}$ There is no significant influence of employment on personal development of youth with disabilities in EMC.

\section{Employment and Disabilities}

Youth with disabilities require vocational qualifications in order for them to function fully in the society. Without these, their job opportunities would be limited. Joblessness for youth with disabilities was higher than for ordinary persons in every society; most of those persons suffering unemployment almost in every nation were persons with disabilities. Their unemployment rate was usually higher than that for persons without disabilities. An example was that some nations of the Asia-Pacific region, had joblessness 
rate of more than $80 \%$ (ILO, 2002). At the same time discrimination education-wise and in vocational advancement could negatively affect their competitiveness in the world of work; resentment about disabilities and isolation being the most recurring barriers to the successful hiring of persons with disabilities (ILO, 2002). Bad attitudes towards youth with disabilities and erroneous misconceptions of employers, like seeing persons with disabilities as less productive than their ordinary age mates, needed lots of help, affected the employer's image, and/or past history as regard employment costs like (construction of ramps, accessible IT), cause a very serious challenge to youth with disabilities hunting for employment (ILO, 2002). This is true despite the fact that the studies have shown evidence that most accommodations were not that costly to firms and also to those-non disabled persons using and benefitting as a result of the assistive work place regulations and policies (Schartz, Hendricks \& Blanck, 2006).

In Sweden, the government had created very strong specific laws to fight all types of discrimination against its citizens with disabilities. In its regulations also, furthering of personal development of persons with disabilities was focused on and worked on their work careers. Samhall was a Swedish state owned cooperation which was commissioned to design employment that enhanced personal growth of individuals who had locomotional or cognitive impairments that caused lessened working power or strength. Samhalls task was controlled by the articles of association and by collective judgment annually and additionally by instructions from the proprietor. Samhalls principle task was the manufacture of materials, offering required and urgent services which would influence the bringing into existence of important employment.

That would boost the personal development of people with functional impairments whose condition had caused reduced working capacity, where the need to do more existed. The filling of vacancies at Samhall Corporation were at the disposal of the Public Service, which looked into the want or desire and directed those with functional impairments in need of employment to work at Samhall (Samhall, 2018). The World Programme of Action for Youth encourages Nations or countries to take positive steps in creating viable environment for youth with disabilities. Article 27 of the Convention for persons with disabilities deals with work concerns by pointing out that persons with disabilities have a right to work just like any other person in the world of work and should not be discriminated against in any way in the work environment.

To quote Sen's (1992) and (2009) term "inability to earn desired income", disabilities might restrain the capacity to make monetary gains. In the theory pertaining to an economy that leisure choice model suggested that the rate at which persons were being hired was anticipated to be downwards for disabled individuals because of higher restrictions of wages and at times because of accessibility of gains and downwards market earnings because of downward production and/or prejudice (Bound and Burkhauser, 1999; Mitra \& Sambamoorthi (2008).

Concerning the attitude towards persons with disabilities, the applicability and the seriousness of employment depended on how culturally this was viewed especially regarding discrimination in the community at a large or in the family, may lessen entry 
to employment (Mitra and Sambamoorthi, 2008). The regulation circumstances were applicable too, for example, were technical rehabilitating plans, insurance or social support plans available. Such plans according to how they were created or made and used could make it easier, block or not influence entry to work for disabled individuals. Persons with disabilities were and had always been part of human communities: " Almost all mass skeletal population had one individual-and often several-whose remains indicated congenital malformations, bones which had not fully healed, missing limbs, or head trauma" (Scheer and Groce, 1990). For many times, it had been noted or believed that Persons with disabilities in primitive communities controlled exceptional and sanctimonious positions in their communities. However, nothing much had been proven or unearthed to establish the truth on those postulations on persons with disabilities necessarily occupying exceptional places in society (Scheer and Groce, 1990).

In any case, the presence of Persons with disabilities occupying those communities did not suggest that they controlled important positions of glory within their groups. As stated by Enns (1999), before the industrialization period, disabled persons worked in family and cottage industry and were able to feed their families well in situations or in a surrounding that had been reached to them had been reachable to them. Throughout the entire industrialization period, numerous disabled persons could no longer produce sufficiently for factory owners that were solely profit-driven; and thus, got kicked out of business to beg from the streets and relied on the assistance of generous individuals (Enns, 1999). The 1843 New Poor Law in England, resulted to Poorhouses of London, that were purposefully created uncomfortable as far as could be and isolated gender-wise married and unmarried to ensure that the have not's never produced more undesirables (Enns, 1999).

The ideas and beliefs of Malttus and Darwin got applied generally as lawful, prompting to the embracing of eugenics idea (ibid) disabled individuals got into institutions in large numbers and continued to stay isolated in homes in Canada despite the fact that the extensive communal living style of the closing of the twentieth country had witnessed numerous disabled people accepted back to society until the 1900s the first and second world wars, disabled individuals didn't matter to society neither in Canada nor in the US. When the wars ended and during the homecoming of the veteran soldiers who had been injured, states were ordered to create policies to respond to the needs of the injured veterans. Then in the 1950's, the emergence of the era of rehabilitation, which focussed on vocational training for the injured soldiers was witnessed.

North Americans define social status through work that is employment, work is seen as a thing of great value and shows a person's perceived value. The first thing Americans will want to know from new acquaintances is what work they do (McLoughlin, et al, 1987). Combined employment characterized by competition was healthy for people with disabilities, for it promised many benefits to them: some being long period interactions with the community and peer employees, enhanced choice and critical thinking ability, more benefits, upgraded status, plus general standards of living (McLoughlin et al 1987, Government of Canada 1999). 
Disabilities and employment cross each other as far as policy and definitions, which were made as regard the job opportunities for persons with disabilities were concerned. Earlier definition of disabilities invariably inferred to an individual's usefulness to society economically, that is in terms of production. This stayed on until the 1980 's when the world health organization started revising the definition of disabilities. Being able to procure work in Manitoba and other provinces continued to block one's ability to get income assistance (MLPD, 1999). Several social factors blocked persons with disabilities from work. A myriad of these challenges, though, have been removed through fighting the negative attitudes and encouraging enhanced accessibility and also accommodation in the work place. However, many more challenges still pin down persons with disabilities to less employment in inferior low paying or seasonal positions, or pigeonholed into structured in-service organizations for persons with disabilities (Government of Canada, 1999).

Many reasons have been suggested for the unequal employment rates. Cyr and Schirle (1999) listed four groups of challenges to work for persons with disabilities: bureaucratic, physical, institutional, and attitudinal. It was true that all these issues were of importance, but this study had only highlighted the political attributes of the problem and has completely shut out the personal "lived experiences" due to joblessness of persons with impairments.

Most of the world's youth with disabilities, terminate their formal education at mid-adolescence, when boys and girls are ready for work. The youth throughout the world are significantly at risk of being jobless, whether in partial or in permanent work, at less wages than grownup workers, particularly in the current economic climate (Groce $\&$ Kett, 2014). Youth with disabilities are in a lot of risks. Looking for a job with little or no education and little or no experience make youth with disabilities less competitive in the world of work. For others, specific physical or cognitive challenges may in addition reduce their work choice. In regard to others, communal discrimination and absence of understanding on the latent qualities of disabled people make managers doubt their hiring.

There is no follow up done as regard employment rates of persons with disabilities (Kett, 2012). In any case, it is estimated that unemployment of adults with disabilities averagely ranged between $40-60 \%$ on the upper side than for ordinary population (UN, 2010b). This is in agreement with the trends in advanced countries with also advanced and highly developed school-to-work schedule and specially kept employment schemes. The international labour organization (ILO) (2002) points out that joblessness rates amongst disabled persons in the poor countries of planet earth was as high as $80 \%$ (ILO, 2002). Joblessness among youthful women with disabilities in the totality of communities averaged $50 \%$ on the higher side than joblessness rates amongst comparatively schooled disabled boys (a double that of male without disabilities).

The status of employment for those with disabilities is in continuous state of flux, and most of these youth likely to be put in work may require little or no apprenticeship and have less chances for promotion. Despite a good education, youth with disabilities 
take much more time to acquire a position of advancement unlike their non-disabled counterparts. In addition, they are always the last to be recruited and sadly firstly fired. This is also evident regarding disabled persons having completed their higher education in the (university) (UNICEF, 2013b), where technical training is accessible; there is always a discrepancy between the training offered and the labour market requirements (Kett, 2012).

Referring to employment figures, however, may mislead because they do not consider unpaid labour. Millions of youthful disabled persons all over the world are employed in family enterprises even though not recognized officially as employed by economists (Groce et al., 2013). They take care of the babies, sick ones; the relatives advanced in age or even attend the garden; flocks, rentals and also do the cooking. Large numbers work within the community doing anything available including begging (Groce et al., 2013). The kind of work may be very important but might not be noted by economists, native persons or surprisingly by their immediate relatives. They are accorded a paltry recognition for the work they accomplish and they have very little or no say as regard the money they earn (UNICEF, 2013b).

\subsection{Theoretical Framework}

This study utilized Sanderson's socio-cultural perspective (2010) and Adams Stacey's Equity theory (1965). According to Sanderson (2010) socio-cultural perspective was a supposition utilized in different disciplines like psychology and utilized to define consciousness of situations concerning persons and their conducts were influenced particularly by their environment collectively and or ethnically. A socio-cultural view point is a standpoint defining or detailing a person's behaviour and cognitive operation as formed partly by their social or culture contact, comprising ethnicity, issues of gender and citizenship. A socio-cultural viewpoint assumption is a wide and yet an important feature in our existence. It occurs to each and every part of our everyday lives. In the study, the theory concerns itself with how the community relates to Persons with disabilities through provision of socio-cultural support services such as education and vocational training, health services, employment and, community perception, and these provisions influence their personal development. Sanderson (2010) observes that how people communicate, understand, relate and cope with one another is partially based on the socio-cultural services they can access from their environment. These socio-cultural services include education and vocational training, health services and employment among others. Our spiritual, mental, physical, emotional, psychological being are all impacted by elements looked into by socio-cultural perspective theory. Persons with disabilities will behave, react and relate the way they are treated by persons without disabilities in the community and the theory ought to guide us on how to handle persons with disabilities; that if we handle them in a proper way, they become useful and productive in the society. This theory is applicable in disability studies in that it affects all persons, those with disabilities and those without disabilities. It is applied when relating to difficult circumstances undergone by those with disabilities, and also as we 
cope with adults and youth with disabilities in our environments. Thus, our spiritual, mental, physical, emotional and psychological natures are all influenced by socio-cultural perspective.

The centre of attention in Adam Stacey's theory of equity (1965) was the determination whether or not the sharing of wealth was equitable. Persons with disabilities could be thought of as relating to persons without disabilities by the later safeguarding the fact that wealth was distributed equitably to avoid one partner feeling that they had been under-rewarded. The theory advances that persons who distinguish themselves as disadvantaged or over-advantaged would be experiencing suffering; this suffering though would lead to attempts to reinstate fairness within the relationship. Equity was about individuals comparing their inputs and outcomes within those of others and then responding to eliminate any inequality.

The paramount parts of exchange relationships in Adams theory were the inputs and outputs. In a scenario where an individual offers his or her services for a salary input may comprise earlier work experiences training or schooling, hard work and preparation. Outcomes may be seen as those things resulting from the exchange. Inputs and outputs must satisfy two requirements before being put into consideration in the assessment of the exchange relationships. Firstly, the being of an input or outcome had to be acknowledged by one or both the groups to the exchange. Secondly, an input or output had to be regarded applicable or admissible to the exchange such as having some marginal utility. Adams advances that persons consider their in and outputs parts in terms of their significance to the person.

Just as Adam Stacey's equity theory, persons with disabilities require fairness, inclusivity and participation in every sphere of the society. Persons with Disabilities have been isolated and mistreated (Anderson, 2004). They are often left out of economic activities despite being a potential source of human capital for the society. In fact, a large proportion of youth with disabilities experience exclusion and abuse almost always and also lack economic and educational opportunities. Their basic rights are ignored and are neither recognized nor accepted by society. Therefore, the principle of equity in terms of resource sharing and provision of socio-cultural support service to the less privileged must be adhered to. Awareness of circumstances surrounding youth with disabilities and how their behaviours were affected by this environment would therefore be determined by how equitable the socio- cultural resources are distributed amongst them as well as among the ordinary persons in the community. The fair inclusion and participation in the society would facilitate positive personal development among youth with disabilities.

The study, therefore, sought to investigate how the socio-cultural support services influenced the personal development of youth with disabilities. This study presumed that these socio-cultural support services may influence personal development of youth with disabilities in Elgeyo-Marakwet County. 


\section{Research Methodology}

Mixed research methodology or triangulation with both quantitative and qualitative research was employed in this study (Stecler et al., 1992). The study utilized mixed methods design. Sequential is one example of mixed method designs (Almeida, 2018). The study was conducted in Elgeyo-Marakwet County. The county borders West Pokot County to the North, Trans-Nzoia and Uasin Gishu Counties to the West and Baringo County to the East. Elgeyo-Marakwet was chosen for this study because, out of its population of 369,270 , there were many (below $10.0 \%$ ) youth with disabilities who were not engaged in any meaningful economic activities such as cleaning, cobbling and tailoring (EMC, county education Office). According to socio-economic atlas of Kenya, 2014, the National Population Census of that year in Elgeyo Marakwet County was 369,270 . The proportion of persons with disabilities in this whole population was $2.8 \%$ (Wiesmann et al, 2014).

Table 1: Showing the Distribution of Target Population

\begin{tabular}{|l|l|c|}
\hline Sub County & In//Out of School & Target \\
\hline \multirow{4}{*}{ Marakwet } & In school & 172 \\
\cline { 2 - 3 } & Out of school & 70 \\
\cline { 2 - 3 } & Sub-Total & 242 \\
\hline \multirow{3}{*}{ Keiyo } & In school & 170 \\
\cline { 2 - 3 } & Out of school & 80 \\
\cline { 2 - 3 } & Sub-Total & 250 \\
\hline Grand Total & & $\mathbf{4 9 2}$ \\
\hline
\end{tabular}

\subsection{Sampling and Sampling Techniques}

This study employed both probability and non-probability sampling techniques. The sample computed was 289 for youth with disabilities in school. To determine the content validity of the instruments, expects in SNE were presented with the research instruments prior to the actual study.

\subsection{Sampling and Sampling Characteristics}

The study applied simple random sampling and purposive sampling techniques in identifying the population of the study. To determine the sample size from the youth, youth with disabilities.

This study employed both probability and non-probability sampling techniques. Krejcie and Morgan's (1970) formulae for determining the sample size was used and the sample computed was 289 for youth with disabilities in school.

\subsection{Research Instruments}

Questionnaire, interview guide, and observational checklist were used to collect data for this study. The questionnaire and interview guide were used to collect data from youth with disabilities, parents, and government Officers. Observational Guide was used to 
find out what types of assistive technologies were available to youth with disabilities as well as the conditions of the environment and the living conditions of the youth with disabilities.

\subsection{Piloting of the Research Instruments}

Piloting was undertaken by the researcher in Uasin Gishu County, using $10 \%$ of the sample. To determine content validity of the instruments, the supervisors were presented with the research instruments prior to the actual study.

\subsection{Reliability}

Cronbach's alpha coefficient was computed and decision made on the reliability index of the questionnaire. The instruments' final indexes were 0.741 and 0.636 for youth with disabilities and parents/guardians questionnaires respectively.

\subsection{Data Collection Procedures}

The researcher identified and trained four research assistants who facilitated in the dispatching of the questionnaires to the research participants.

\subsection{Data Analysis Procedures}

Data was analysed quantitatively and qualitatively using descriptive statistical techniques. Descriptive statistics included measures of means, frequencies, and percentages using the statistical package for social sciences (SPSS version 27) computer program.

\section{Results}

\subsection{Socio-demographic Information}

This section presents the socio-demographic data of the participants. The age, gender, level of education of the participants, type of the disability of the respondents and where they obtained their assistive technologies have been highlighted. The same information has been provided for the parents and guardians of youth with disabilities. In addition, the marital status, family income and programs available for youth have been depicted.

\subsubsection{Gender of Youth with Disabilities in and Out of School}

According to the study findings, females comprised a higher proportion of youth with disabilities in school. The study found that 104 (36.0\%) of youth with disabilities were female while $77(26.6 \%)$ were male. The youth with disabilities out of school were 52 $(18.0 \%)$ male and $56(19.4 \%)$ female respectively. Higher proportions of youth with disabilities were also female. This was in agreement with UNESCO (2003) estimation that $98 \%$ of disabled children living in poor countries were not in school while $99 \%$ of female children with disability could not read or write. The highest proportions of youth with disabilities in school were those aged between 30-35 years old followed by those who 
were between 15 years old to 20 years. These comprised of 60 (33.1\%) and $49(27.1 \%)$ respectively. These findings revealed that youth with disabilities stay in school longer than expected. These findings concurred with Newman, Wagner, Knokey, Marder, Nagle and Shaver (2011) findings which said that students with disabilities lagged behind the general population in high school graduation and post-secondary and took eight years instead of four years to complete their degree studies.

The study findings in Table 2 further showed that youth with disabilities in school formed the highest proportion with 66 (38.2\%) being at the primary level while $51(28.0 \%)$ were found at the secondary level. Only 15 (8.3\%) were found at the degree level. Among the youth with disabilities out of school 28 (25.9\%) reached form four level and $23(21.3 \%)$ attained primary level education. youth with disabilities in and out of school at the degree level were more or less the same with $15(8.3 \%)$ and $14(13.0 \%)$ in and out of school respectively. The study findings showed that access to higher education still remained a challenge to youth with disabilities. These findings concurred with Organization for Economic Co-operation and Development (OECD, 2003), which indicated that continuing inaccessibility to higher education institutions curtails the ability of youth with disabilities to participate in vocational training courses. This might arise from the educational establishments themselves which were always difficult to access and generally absence of accommodations for youth with disabilities and lack of assistive technologies. These findings seemed to agree with Groce (2004) whose findings indicated that, some families did not feel that youth with disabilities should receive education, often believing that, youth with disabilities were incapable of learning (Groce, 2004). The World Programme of Action for Youth (WPAY) reiterated the importance of paying great interest to the learning of disabled youth by adopting the UN charter on Persons with disabilities. In Kenya, there is hope because, the nation has ratified several laws relating to disabled persons whose rights are now in the public discourse and policies are in place to guard the same (Kenya Constitution, 2010).

\subsection{Employment of Youth with Disabilities}

\subsubsection{Occupation of Youth with Disabilities in and Out of School}

The study findings gave some evidence of financial stress undergone by students with disabilities. Students with disabilities were doing some low paying jobs to get finances to keep surviving. The research findings indicated that $9.4 \%$ of the students were working as cleaners, cobblers and tailors, despite the fact that they were in school. The study findings revealed that youth with disabilities in school were forced to do some jobs to raise money for their upkeep. As shown in Table 2, 164(90.6\%) were students while 8 $(4.4 \%)$ were cleaners or carpenters. Others were doing jobs such as business $2(1.1 \%)$, farming 2(1.1\%) and tailoring $2(1.1 \%)$.

Table 2: Occupation of Youth with Disabilities in School

\begin{tabular}{|l|c|c|}
\hline Occupation & N & \% \\
\hline Business & 2 & 1.1 \\
\hline Carpenter/cleaner & 8 & 4.4 \\
\hline
\end{tabular}


William Kibet Kurumei, Collins O. Ogogo, Edward Kochung, Cecilia Kimani ASSESSMENT OF THE INFLUENCE OF EMPLOYMENT ON PERSONAL DEVELOPMENT

OF YOUTH WITH DISABILITIES IN ELGEYO-MARAKWET COUNTY, KENYA

\begin{tabular}{|l|c|c|}
\hline \hline Farming & 2 & 1.1 \\
\hline Cobbler & 3 & 1.7 \\
\hline Student (no occupation) & 164 & 90.6 \\
\hline Tailoring & 2 & 1.1 \\
\hline Total & 181 & 100.0 \\
\hline Occupation of Youth with Disabilities out of School & $\mathbf{N}$ & $\mathbf{\%}$ \\
\hline Business & 9 & 8.3 \\
\hline Farmer & 26 & 24.1 \\
\hline Others & 33 & 30.6 \\
\hline Teacher & 40 & 37.0 \\
\hline Total & 108 & 100.0 \\
\hline
\end{tabular}

The results of Table 2 are in agreement with OECD (2003) whose findings revealed that continuing inaccessibility of higher education might be due to lack of appropriate facilities and inadequate financial resources from their sponsors. Observations made were that, youth with disabilities at home performed activities of daily living like weeding in the farm and herding animals. However, some were idle and simply staying at home. In one particular incident, a youth with disability was found weeding in the maize farm while supporting himself with one crutch. The study also revealed that youth with disabilities out of school only accessed some few selected jobs which comprised farming $26(24.1 \%)$, teaching $40(37.0 \%)$ and a paltry $9(8.3 \%)$ were involved in business. These findings were in agreement with (Groce et al 2013), who revealed that very many youthful disabled persons throughout the world worked in their household businesses such as farms, workshops and such work went unrecognised by local communities, economists and their families. UNICEF (2013b) stated that youth with disabilities received little or no recognition for what they did and did not have any control or say whatsoever on the money they made.

On the other hand, students with disabilities who had left school seemed relegated to particular jobs only. From the study findings, there was evidence of some kinds of work reserved for people with disabilities as they were not able to handle some of the work being done by people without disabilities. The results of Table 2 indicated that the occupations available to youth with disabilities were mainly teaching 40(37.0\%), farming $26(24.1 \%)$ and business at $9(8.3 \%)$. Others included a conglomeration of other occupations such as nursing, politics, hair dressing, and telephone operations all below $2 \%$ (Table 2). The foregoing results indicated that some occupations had been reserved only for youth with disabilities.

Additionally, suitable relevant legislation has been established, specifically for fighting discrimination against disabled persons (Swedish Government, 2018). In a nutshell, provision of employment opportunities by NGOs, CBOs and Government was a self-directed sustainable intervention ensuring independence, economic freedom, social freedom, psychological freedom and boosted self-esteem for youth with disabilities. The provision of the Kenya National fund for persons with disabilities might not be sustainable in the long run for the population of persons with disabilities is ever 
increasing. It was prudent to provide employment opportunities to PWDs than funding them for upkeep since funds might be inadequate or depleted.

Simple regression was used to model and obtain how much the employment contributed to personal development of youth with disabilities.

Table 3: Regression results

\begin{tabular}{|l|c|c|c|c|c|}
\hline Model & R & R Square & Adjusted R Square & Std. Error & \% Contribution \\
\hline Employment & 0.444 & $19.7 \%$ & 0.1942 & 0.792283 & 19.70327 \\
\hline
\end{tabular}

Source: Research findings, 2016

\section{Summary, Conclusions and Recommendation}

Provision of complement to youth with disabilities was crucial to the wellbeing of every disabled individual. Now with mainstreaming and inclusion Concepts, access is access is fair. Whereas the Kenya Government, through MOE and relevant departments have pushed access a notch higher, there was nothing much yet to be celebrated so far.

\subsection{Conclusion}

The results of the study led to the following conclusions, that the efficiency of employment was important to the well-being of persons with disabilities. Provision of employment revealed that YWDs influenced emotional well-being, personal development of youth with disabilities.

\subsection{Recommendation}

Based on the study findings, the following recommendation are made.

\subsection{Employment and Productivity}

Youth with disabilities needed provision of as much employment as possible with competitive salaries. Those who might not secure formal employment could be assisted through facilitation of access to funding mechanisms. Lucking and Fabian (2000) indicated that students with disabilities who took part in apprenticeship training and special needs education in inclusive environments had a higher probability of being competitively hired than those students who did not engage in such exercises (Luecking and Fabian, 2000). Self-employment could be implemented using a multi-sector approach that fostered economic inclusion of people with disabilities including activities such as continuous assessment, referral and development of economic inclusion of people with disabilities and guaranteeing a safe environment by installing safe accessible water and sanitation. To improve their, productivity at work, provision of assistive technologies needed implementation. There was need for designers of disability products to enhance research on the most appropriate assistive technologies for people with disabilities.

\section{Conflict of Interest Statement}

The authors declare no conflicts of interests. 


\section{References}

Adams, J. S. (1965). Inequity in social exchange. In L. Berkowitz (Ed.), advances in experimental psychology pp. 267-299. New York: Academic Press.

African Union of the Blind (AFUB) (2007). State of disabled people's Rights in Kenya Report: AFUB Secretariat, Nairobi Kenya.

Anderson E. (2004). Public Policy Marketing process: Praeger publisher USA page 2

Borg, J., Berman-Bieler, R., Khasnabis, C., Mitra, G., Myhill, W., \& Raja, D. S. (2015). Assistive Technology for Children with Disabilities: Creating Opportunities for Education, Inclusion and Participation. (pp. 6-8). UNICEF.

Bound, J., and R. V. Burkhauser (1999). Economic Analysis of Transfer Programs Targeted on People with Disabilities. In Handbook of Labour Economics, vol. 3C, 3417-3528. North Holland: Elsevier Science.

Cyr, N. and Schirle, T. (1999). The Employment and Income Assistance Program: Removing Employment Barriers and Disincentives to Work. Winnipeg: Manitoba League of Persons with Disabilities.

Enns, Henry (1999). “The Historical Development of Attitudes Toward the Handicapped: A Framework for Change". An excerpt from Perspectives on Disability and the Helping Process. Chapter 11:175-186, in David S Freeman and Bary Trute, eds, Treating Families with Special Needs, Ottawa, Alberta Association of Social Workers. Government of Canada, (1999). Future directions: To Address Disability Issues for the Government of Canada. Working together for full Citizenship.

Groce, N. E. \& Kett, M. (2014). Youth with Disabilities. Leonard Cheshire Disability and Inclusive Development Centre: working Paper No. 23

Hollar, D. (2005). Risk behaviors for varying categories of Disability in NELS: 88. The Journal of School Health, 75(9), 350-359.

Human Resources Development Canada (HRDC) (2002).Advancing the Inclusion of Persons With disabilities. Hull, Quebec International Labour Organization. (2002). Information Note. ILO/Japan Technical Consultation Meeting on Vocational Training and Employment of People with Disabilities in Asia and the Pacific. 1416 January 2003. Bangkok. Available at: http://www.ilo.org/public/english/region/asro/bangkok/ability/back ground.htm

Kett, M. (2012). Vocational s development for youth living with disabilities in four developing countries. Background paper prepared for the Education for all Global Monitoring Report. Paris: UNESCO. Accessed May 9, 2014. http://unesdoc.unesco.org/images/0021/002178/217882e.pdf

Luecking, R. \& Fabian, E. S. (2000). Paid Internships and Employment Success for youth in transition. Career development for exceptional Individuals.

Mcloughlin, Cave S., J. Garner, B., Callahan, M. (1987).Getting Employed, Staying Employed: Job Development and Training for Persons with Severe Handicaps. Baltimore: Paul H. Brooks Publishing Co. 
Mitra, S., and Sambamoorthi, U. (2008). Disability and the Rural Labor Market in India: Evidence for Males in Tamil Nadu. World Development 36(5):934-952.

Roggero, P., Tarricone, R., Nicoli, M., \& Mangiaterra, V. (2005). EmploymentE Youth with Disabilities: Sharing Knowledge and Practices. Washington, D.C.: World Bank.

Samhall (2018). About Samhall. Retrieved from Swedish Company: https://samhall.se Sanderson, Catherine A. (2010). Social Psychology. New York, John Wiley \& Sons.

Schartz, H. A., Hendricks, D. J., \& Blanck, P. (2006). Workplace accommodations: Evidence based outcomes. Work, 27, 345-354.

Scheer, J; Groce, N (1990). Impairment as a Human Constant: Cross Cultural and Historical Perspectives on Variation. Journal of Social Issues, Vol 44(1): 23-37.

Swedish Government. (2018, January). Dignity and democracy in Sweden. Retrieved from Sweden's disability Policy: https://sweden.se/wpcontent/uploads/2013/11/Disability-policy-in-Sweden-high-res1.pdf

UNICEF (2013b). Fact Sheet on Children and Young People with Disabilities. New York: UN. $\begin{array}{llll}\text { Accessed } & \text { May } & 8 & 2014 .\end{array}$ http://www.unicef.org/disabilities/files/Factsheet A5 Web NEW.pdf. 
William Kibet Kurumei, Collins O. Ogogo, Edward Kochung, Cecilia Kimani

ASSESSMENT OF THE INFLUENCE OF EMPLOYMENT ON PERSONAL DEVELOPMENT

OF YOUTH WITH DISABILITIES IN ELGEYO-MARAKWET COUNTY, KENYA

Creative Commons licensing terms

Authors will retain the copyright of their published articles agreeing that a Creative Commons Attribution 4.0 International License (CC BY 4.0) terms will be applied to their work. Under the terms of this license, no permission is required from the author(s) or publisher for members of the community to copy, distribute, transmit or adapt the article content, providing a proper, prominent and unambiguous attribution to the authors in a manner that makes clear that the materials are being reused under permission of a Creative Commons License. Views, opinions and conclusions expressed in this research article are views, opinions and conclusions of the author(s). Open Access Publishing Group and European Journal of Special Education Research shal not be responsible or answerable for any loss, damage or liability caused in relation to/arising out of conflict of interests, copyright violations and inappropriate or inaccurate use of any kind content related or integrated on the research work. All the published works are meeting the Open Access Publishing requirements and can be freely accessed, shared, modified, distributed and used in educational, commercial and non-commercial purposes under a Creative Commons Attribution 4.0 International License (CC BY 4.0). 